its parts and the story told gives the essence, the entité, of the region.

This book describes the landscape in great detail and is thorough in defining type areas and the effect of man. The cultural landscape is given less attention because the low population density compels less human emphasis. The book is a doctoral thesis based on an intensive search of the literature (there are 30 pages of bibliography), a detailed interpretation of maps, diagrams, air and satellite photographs and three extensive visits. The author has been fascinated by the sudden changes that the traveller sees in this land of ice and fire, with its awesome interior plateau more like a moonscape than any landscape on Earth.

The first part (100 pages) of the book is a national compendium, defining terms, describing landscape features, mapping climatic elements and listing population and employment changes and their products up to 1970. The second part of the book (40 pages) describes nine main landscape types. The third part (about half the book) extends this, with 30 geographically located regions, some with further subdivision. It is not easy to know where the author is in these descriptions, although the many diagrams and sketch maps are a great help. It is therefore essential to have the nine Icelandic maps $(1: 250,000)$ alongside the book. To capture the spirit of place, the reader should also have some of the many beautifully produced volumes of colour photographs of Iceland.

The book is a scholarly work and is. considering how crammed with information and references, remarkably easy to read.

H. Lister

H. Lister is Reader in Physical Geography at the University of Newcastle upon Tyne. UK.

\section{State of the oceans}

The Health of the Oceans. By Edward D. Goldberg. Pp. 172. (Unesco Press: Paris, 1976.)

EDWARD GOLDBERG's book arose as a result of a recommendation made in 1973 at the time of the first meeting of the Intergovernmental Oceanographic Commission's International Coordination Group for the Global Investigation of Pollution in the Marine Environment. As originally conceived, it was intended to fulfil the role of a baseline, or statement on the status of pollution in the marine environment, against which to judge the changing health of the oceans within a continuing review of marine pollution as part of the Global Investigation of Pollution in the Marine Environment. A great deal of useful information to that end is contained within the ten chapters, but the book has nevertheless been written against a much broader conception of the problem than was originally intended.

There is an effort to produce a health status report; but also much of a speculative nature written to examine causes, to reflect on philosophy and to make tentative suggestions about future problems and their solutions. The book dwells at length on the lessons to be learned from the successful regulation of radioactive waste disposal to the oceans, on the mercury problem, and on DDT and oil. The author clearly believes that much could be gained by attacking other pollution problems along similar lines to those used in the UK in relation to radio- activity, including the application of 'critical path' philosophy to the design and implementation of monitoring programmes; a suggestion with which the reviewer has much sympathy.

Halogenated hydrocarbons, radioactivity, heavy metals and oil all receive treatment in separate chapters, supported by chapters which deal collectively with marine pollution dynamics, modelling (especially mass balance studies), monitoring and prediction. Among the problems which obviously concern the author, and which he returns to throughout the text, are the long term significance of small changes in pollutant concentration in the occans, the difficulty in uncquivocally establishing such trends, and our reaction time in taking remedial action when the system's reaction time itsclf may be long and, as a consequence, re-establishment of normal concentrations may take a long time: a time during which damage to the system may appear which will take longer to rectify and which may have serious consequences as yct unpredictable.

There is a carefully written preface by Alan Holden, and readers of the book would do well to peruse it before tackling the text. One must conclude, however, that Professor Goldberg has picked his way through something of a minefield without much more than superficial wounds, and produced a thought-provoking text on the way.

Alan Preston

Alan Preston is Deputy Director of Fisheries Research in the Ministry of Agriculture, Fisheries and Food based at Lowestoft Lahoratories, and Chairman of the UK Marine Pollution Monitoring Management Group.

\section{Updating nematodes}

Physiology of Nematodes. Second Edi tion. By D. L. Lee and H. J. Atkinson.

Pp. $x+215$. (Macmillan: London, October, 1976.) £5.95.

When Donald L. Lee wrote the first edition of this book it was a milestone. Although of modest size, it was the first attempt to organise the subject, stimulated great interest and highlighted critical areas for the research efforts of others. Now, with his colleague, Howard J. Atkinson, a second edition has been published. In the eleven years between the editions and partly because of the impact of the first, there have been numerous papers, reviews and books on nematode physiology. This new edition still presents an excellent introduction for undergraduates, as it is designed to do, but those professionally involved with nematodes will spot some overgeneralisations and omissions.

The chapters include: introduction; cuticle, moulting and growth; feeding and digestive physiology; metabolism (a particularly comprehensive section); osmotic and ionic regulation; excretion; reproductive physiology and hatching; neuromuscular physiology: locomotion; sense organs and behaviour. There are 77 figures, less than 40 of which were in the first edition, and there are 246 references instead of the earlier 161 . The references are only representative and no attempt is made to credit individual workers in particular fields. There are few typographical errors but nematode names are occasionally mis-spelt (four in chapter 4) and there are seven errors in the appendix listing nematodes. The text and figures have the same clear, concise and very readable features of the first edition.

Specific points are sometimes unclear: nematodes are still credited with constant cell numbers but this is a much compromised notion now (p27). Predatory nematodes are poorly discussed in the light of the most recent studies (p44). Various reports have shown that the 'lens' of ocelli is, in fact, the photoreceptive rhabdomere and that no lens exists. The figure of Deontostoma californicum with a lens is particularly unfortunate as this was the species first shown not to have a 'lens'. Photic response for two species is ignored (p68) which makes incorrect the statements on their behaviour.

At $£ 5.95$ this book deserves to enjoy good sales, and it will be widely read.

Neil A. Croll

Neil Croll is Professor of Parasitology and Director of the Institute of Parasitology, McGill University, Montreal, Quebec, Canada. 